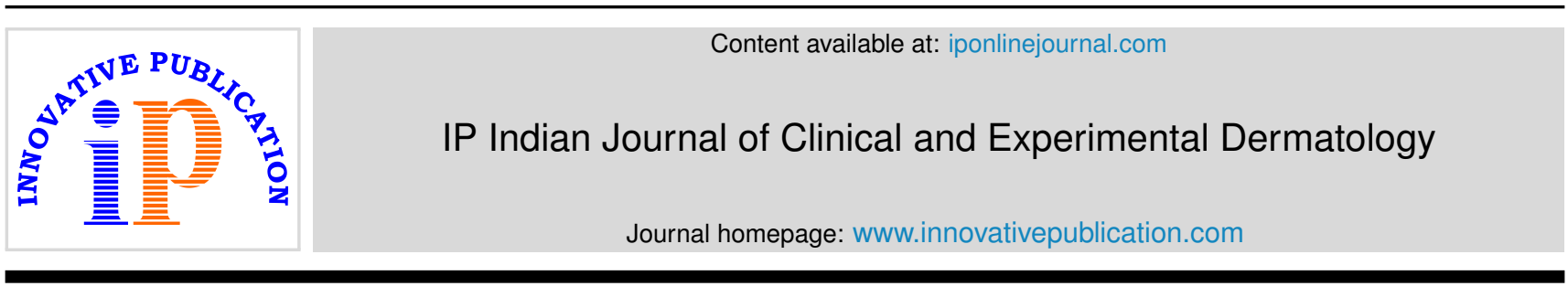

Original Research Article

\title{
Pattern of skin diseases among dental and nursing students in a tertiary care centre
}

\author{
Neetha Latha ${ }^{1, *}$, Vijaya Bharathi ${ }^{1}$, Nivin Simon ${ }^{1}$, S Rajagopal ${ }^{1}$, S Murugan ${ }^{1}$ \\ ${ }^{1}$ Dept. of Dermatology, Sree Mookambika Institute of Medical Sciences, Kulasekharam, Tamil Nadu, India
}

\section{A R T I C L E I N F O}

\section{Article history:}

Received 21-07-2019

Accepted 02-08-2019

Available online 14-09-2019

Keywords:

Seborrheic dermatitis

Screening

Acne vulgaris

\begin{abstract}
A B S T R A C T
Introduction: Adolescents bother more about their appearance. Certain skin diseases are common in this particular population (seborrheic dermatitis, acne vulgaris and hair fall etc.) which led them to worry and upset. To assess the integrity of the problem we conducted a study among the students of dental and nursing college adjacent to our institution.

Aims and Objectives: To find out the pattern of occurrence of skin diseases among dental and nursing students in a tertiary care centre.

Materials and Methods: A cross sectional study was conducted among nursing and dental students adjacent to our institution. Full screening for skin lesion was done among the study subjects.

Results: Out of the 561 study subjects 423 had skin lesions: In these majority of the subjects had seborrhoeic dermatitis (including scalp and face).

Conclusion: This study help to assess their general health status as skin is the mirror of systemic diseases and also to frame the guidelines and hygienic measures be followed by the students in similar situation in future.
\end{abstract}

(C) 2019 Published by Innovative Publication.

\section{Introduction}

Skin is the largest organ of the body, exposed and vulnerable to most of the obnoxious environments. As per American pediatric association, up to 21 years comes under adolescent period. ${ }^{1}$ Adolescents are studying population and more bother about their appearance. Certain skin diseases are common in this particular population (seborrhea dermatitis, acne vulgaris and hair fall etc.) which led them to worry and upset. Their self-esteem is lost and has an impact on their performance in their study. To assess the integrity of the problem we conducted a study among the students of dental and nursing college adjacent to our institution. Seborrheic dermatitis, Pediculosis, Acne vulgaris, pityriasis versicolor and palmoplantar warts are common in this age group. Seborrheic dermatitis is a type of papulosquamous disorders seen affecting both sexes with a male preponderance. ${ }^{1-3}$ Seborrheic dermatitis typically has affection for the sebum rich areas of the skin. The disease clinically manifests

\footnotetext{
* Corresponding author.

E-mail address: nithyalatha.90@gmail.com (N. Latha).
}

with erythematous and greasy looking scales that affect the regions of the scalp, face, chest, back and flexural areas. The organism Malassezia fur fur, a type of yeast has been implicated in playing a role in triggering the inflammation and hyper proliferative epidermal responses that lead to the manifestations. Head lice are usually located on the scalp, body lice along seams of clothing and crab lice in the pubic area. It is an infestation of the hairy parts of the body with the eggs, larvae or adults of lice. This insect feed on human blood during crawling stage which can result in severe itching. Acne vulgaris is a long-term skin disease that occurs when hair follicles are clogged with dead skin cells and oil from the skin. It is caused by propionibacterium acne. It is characterized by blackheads, white heads, papules, pustules, nodules, and cysts and scarring. Pityriasis versicolor is one of the commonest fungal infections of the skin caused by Malassezia species. ${ }^{2,3}$ This is a superficial infection and does not involve the deeper layers of the skin. The Malassezia species is a part of the normal skin referred to as the skin commensal; but under the influence of various 
factors like the environmental, genetic, and immunological factors it can change itself into the pathogenic hyphal form. Pityriasis versicolor have a characteristic rash that is well demarcated, thin, scaly plaques that can be hypopigmented, hyperpigmented, or erythematous. ${ }^{1,2}$ It is a mild chronic superficial fungal infection of the stratum corneum that is characterized by discoloration of skin that is patchy and scaly. ${ }^{4-6}$ The organism that is responsible for the disease is Malassezia fur fur also known as the pityrosporum which is yeast like lipophilic fungus. The main lesion is a macule that is variable in nature, either hypopigmented or hyperpigmented with a characteristic covering of branny scales Deep palmoplantar warts also are termed myrmecia. ${ }^{7}$ It starts with small shiny papules and progress to deep entophytic, well defined, round lesions; with a rough keratotic surface. They tend to be more painful because they grow deeper than common warts. Myrmecia warts are usually found on weight-bearing areas, such as the metatarsal head and heel. On the hand, they tend to be subungual or periungual warts. ${ }^{7,8}$

\section{Aims and Objectives}

To assess the pattern of occurrence of skin diseases among dental and nursing students in a tertiary care centre.

\section{Materials and methods}

\subsection{Study design}

Cross sectional study

\subsection{Study setting}

Department of Dermatology Venereology and Leprosy, Sree Mookambika Institute of Medical Sciences, Kulasekharam.

\subsection{Study population}

Five hundred and sixty one students from a dental college and a nursing institution adjacent to our institution of Sree Mookambika Institute of Medical Sciences, Kulasekharam. All of them are in the age group of 17- 22 years of age.

\subsection{Study period}

10 days between 16/03/2019 to 25/03/2019

Sample size : 561

Sampling Technique: Convenient sampling

Study Procedure: Complete history and thorough clinical examination was done.

Following parameters were assessed:

Skin, Hair and Nail inspection

1. Site

2. Number of lesions

3. Pattern
4. Type

5. Scaling

6. Colour change

7. Distribution

\section{Method(s)/technique(s)/instrument(s) etc.}

\subsection{Clinical examination}

By Inspection

1. Site of the lesion

2. Number of the lesion

3. Type of the lesion

4. Colour change

5. Scaling if present

\subsection{Direct examination}

1. For fungal infections-KOH scrapping

2. For parasitic infection-Demonstration of organism

3. For bacterial infection-Culture, grams stain

4. For viral infection-Tzanck's test

5. For nevus- Diascopy

6. Woods lamp examination

\subsection{Instruments}

1. Hand lens

2. Torch, hand lens

Data entry and Analysis: Data was entered in Microsoft excel sheet and was analysed using Spss version 16.0

\section{Results}

Out of five hundred and sixty one students screened in this study, only fifty ( $8.9 \%)$ were boys and five hundred and eleven were girls $(91 \%)$ (1:11 ratio). So it is a female preponderance study. Out of the 561 study subjects 423 had skin lesions: In these adolescents and young adults seborrhoeic dermatitis (including scalp and face) tops the list with 272 cases.(48.5\%). Incidence of pediculosis among this population was found with 98 students in 3 boys and 77 girls $(17.5 \%)$. Acne vulgaris was present with 65 students (8 males and 57 females) and constitutes $11.6 \%$ in this study. Palmoplantar warts were present with 37 students which come around $6.6 \%$ in this study. Pityriasis versicolor was present with 12 students (2.1\%).138 students among these 561 who were screened, remained dermatologically healthy and were having no complaints

Conditions like hyperhidrosis, dermatophytic infections, polymorphous light eruption, contact dermatitis, eczema were other disorders found among small number of students... 


\section{Discussion}

The students were screened for skin diseases are between the age group of 17-22. (Adolescent and young adult period). This is the period in which lots of interplay of hormones, appearance of secondary sexual characteristics occur. These alterations may be the cause of certain types of skin diseases during this stage.

It is mainly a female preponderance study. So diseases like pediculosis were in an increased incidence $(17.5 \%)$ owing to female population and their long and dense hair and difficulties in cleaning their head regularly. Incidence of pediculosis was seen in 5 boy students also.

These hormones are responsible for increased sebaceous activities. This could be the reason for the increased incidence of seborrhoeic dermatitis in this population to the extent of $48.5 \%$. This is far high than the previous studies ${ }^{2,3}$

Next to seborrhoeic dermatitis and pediculosis, Acne vulgaris was present in 65 students with an $11.6 \%$ incidence (6 male and 49 female). Acne vulgaris is also due to increased sebaceous activity and secondary bacterial infection. So one could expect a raised incidence of acne vulgaris in this adolescent and young adult population. The incidence of acne vulgaris is lesser than the Nigerian study. ${ }^{3}$ Three of these boys recently tested for scabies before this screening. Programme. Pityriasis versicolor was found with $2.1 \%$ among these students. Other conditions like dermatophyte infections, hyperhidrosis, contact dermatitis, polymorphous light eruptions and eczema were found among few students. This was also similar to other studies ${ }^{9,10}$

Conditions like seborrhoeic dermatitis and acne vulgaris have a predilection for adolescence and young adults owing to their hormonal activity. Infestation like pediculosis and scabies can be expected in a living condition where sharing of fomites which is prevalent in a hostel situation as well as dermatophyte infection. But unusually a high prevalence of palmoplantar warts $(6.6 \%)$ was seen among this population. This prevalence is far exceeding than the studies among students elsewhere and not mentioned in other studies ${ }^{11-14}$

\section{Conclusion}

This type of studies reveals the dermatological condition of the adolescents and young adults in a hostel setup. This will help to assess their general health status as skin is the mirror of systemic diseases and also to frame the guidelines and hygienic measures be followed by the students in similar situation in future.

\section{Source of Funding}

None.

\section{Conflict of Interest}

None.

\section{References}

1. Millington GW, Graham-Brown RA. Skin and skin disease throughout life. In: BT, BS, CN, G, editors. Rooks Textbook of Dermatology. vol. 18. Wiley-Blackwell ; 2010,. p. 41-42. 8th ed.

2. Memon, Kn, Soomro RA, Ansari MS. Pattern of skin diseases in patients visiting a tertiary care health facility at Hyderabad,Pakistan. $J$ Ayub Med Coll Abbottabad. 2011;23:37-46.

3. AG, Reid OP, Bogino AJ, Wondewosen EA, Dessu L, BK. Pattern of skin diseases in children attending a dermatology clinic in a referral hospital in Wolaita Sodo, southern Ethiopia. BMC Dermatol. 2019;19(1). Published. Available from: 10.1186/s12895-019-0085-5

4. Yaseen U, Hassan I. Prevalence of various skin disorders in school going children of Kashmir valley of NorthIndia: A cross sectional study. Indian J Paediatr Dermatol;.

5. Emodi LJ, Ikefuna AN, Uchendu U, Duru UA. Skin diseases among children attending the out patient clinic of the University of Nigeria teaching hospital, Enug. Afr Health Sci. 2010;10(4):362-366.

6. Aboud AM, Nigam PK. Wart (Plantar, Verruca Vulgaris, Verrucae). In: StatPearls [Internet. StatPearls Publishing ; 2019,. Updated.

7. Campbell A, Tabrizi J, Garland S, Marks S, R. Warts are not merely blemishes on the skin: A study on the morbidity associated with having viral cutaneous warts. Australas J Dermatol. 2003;44:169173.

8. Gupta AK, Batra R, Bluhm R, Boekhout T, Jr D, TL. Skin diseases associated with Malassezia species. J Am Academy Dermatol. 2004;51(5):785-98.

9. Marcon MJ, Powell DA. Human infections due to Malassezia spp. Clin Microbiol Rev. 1992;5(2):101-120.

10. Guho E, Boekhout T, Ashbee HR, Guillot J, Belkum AV, Faergemann J ; 1998,.

11. Bonifaz A, Gmez-Daza F, Paredes V, Ponce RM. Tinea versicolor, tinea nigra, white piedra, and black piedra. Clinics in dermatology. 2010;28(2):140-145.

12. Sharma S, Bassi R, Sodhi MR. Epidemiology of dermatosesin children and adolescents in Punjab, India. J Pak Assoc Dermatol. 2012;22:224233.

13. RA S. Superficial fungal infections ; 2004,.

14. Yaseen U, Hassan I. Prevalence of various skin disorders in school going children of Kashmir valley of North India: A cross sectional study. Indian J Paediatr Dermatol. 2013;14:67-72.

\section{Author biography}

Neetha Latha Junior Resident

Vijaya Bharathi Junior Resident

Nivin Simon Senior Resident

S Rajagopal Senior Resident

S Murugan Professor and HOD

Cite this article: Latha N, Bharathi V, Simon N, Rajagopal S, Murugan S. Pattern of skin diseases among dental and nursing students in a tertiary care centre. Indian J Clin Exp Dermatol 2019;5(3):225-227. 